\title{
MODOS DE FAZER HISTÓRIA DA EDUCAÇÃO: PENSANDO A OPERAÇÃO HISTORIOGRÁFICA EM TEMAS REGIONAIS
}

\author{
Terciane Ângela Luchese \\ Universidade de Caxias do Sul, Brasil.
}

\begin{abstract}
Resumo
No presente texto estão sistematizadas reflexões produzidas no decurso dos processos de pesquisa que tenho desenvolvido em História da Educação, com ênfase em termas regionais. $O$ objetivo é apresentar pressupostos e alternativas metodológicas que tem orientado a condução das pesquisas, construídas especialmente a partir do vínculo teórico com autores da Nova História, com ênfase, na História Cultural. Restrinjo-me aos documentos escritos e, portanto, à análise documental, para partilhar as dimensões metodológicas que tenho considerado na produção de pesquisas em História da Educação.

Palavras-chave: metodologia, análise documental, pesquisa em história da educação, regional.
\end{abstract}

\section{MODES TO MAKE HISTORY OF EDUCATION: A HISTORIOGRAPHICAL OPERATION THINKING IN REGIONAL RESEARCH}

\section{Abstract}

This present paper systematizes produced reflections in the processes course of research that I have developed in the history of education, with a regional emphasis. The goal is to share assumptions and methodological alternatives that has guided the research conduct, especially built from theoretical bond with authors of the New History, with an emphasis in Cultural History. I restrict my view to written documents and, therefore, to the documentary analysis, to share the methodological dimensions that I have considered in the production of my studies de history of education.

Key-words: methodology, documentary analysis, research in the history of education, regional.

\section{MODOS DE HACER HISTORIA DE LA EDUCACIÓN: PENSANDO LA OPERACIÓN HISTORIOGRÁFICA EN INVESTIGACIONES REGIONALES}

\section{Resumen}

El presente texto sistematiza reflexiones producidas en el transcurso de los procesos de investigación que he desarrollado en historia de la educación, con énfasis regional. El objetivo es 
compartir presupuestos y alternativas metodológicas que han orientado la conducción de las investigaciones, construidas especialmente a partir del vínculo teórico con autores de la Nueva Historia, con énfasis en la Historia Cultural. Restrinjo mi mirada a los documentos escritos y, por tanto, al análisis documental, para compartir las dimensiones metodológicas que he considerado en la producción de mis estudios en Historia de la Educación.

Palabras-clave: metodología, análisis documental, investigación en historia de la educación, regional.

\section{MODES DE FAIRE DE L'HISTOIRE DE L'ÉDUCATION: PENSANT L'OPÉRATION HISTORIOGRAPHIQUE EN RECHERCHES RÉGIONALES}

Résumé

Ce texte ci systématise des réflexions menées au décours des procès de recherche que j'ai développés en histoire de l'éducation, en mettant l'accent sur l'aspect régional. L'objectif est celui de partager des hypothèses et des alternatives méthodologiques qui ont orienté la conduction de la recherche, construites, spécialement, à partir du lien théorique avec des auteurs de la Nouvelle Histoire, en mettant l'accent sur l'Histoire Culturelle. Je borne mon regard aux documents écrits, donc, à l'analyse des documents, pour partager les dimensions méthodologiques que j'ai considérées lors de la production de mes études à Histoire de l'Éducation.

Mots-clé: méthodologie, analyse des documents, recherche en histoire de l'éducation, régional. 


\section{Considerações iniciais}

presente texto sistematiza reflexões produzidas no decurso dos processos de pesquisa que tenho desenvolvido em História da Educação. O objetivo é o de apresentar pressupostos e alternativas metodológicas que têm orientado a condução das pesquisas. Acredito que seja relevante pensar sobre os modos de fazer pesquisas tendo como objeto a educação, especialmente aquelas contingenciadas pelo recorte regional.

Com relação às investigações que tenho desenvolvido, meu modo de operar a produção historiográfica tem sido orientada por alguns pressupostos. Identifico-me como alguém que tem produzido pesquisas regionais. Regionais por que se limitam a investigar processos educativos em um espaço geográfico delimitado, produzido pelas relações de poder, pelas práticas culturais e históricas reinventadas por grupos humanos que ali vivem e viveram. Assim,

definir região é pensá-la como um grupo de enunciados e imagens que se repetem, com certa regularidade, em diferentes discursos, em diferentes épocas, com diferentes estilos e não pensá-la em uma homogeneidade, uma identidade presente na natureza. (Albuquerque Júnior, 2011, p. 35)

Penso que o estudo regional esteja intersectado pelas redes de contextos e relações em diferentes âmbitos espaciais: local, regional, nacional e internacional. Braudel (2002) ressaltava a importância de o historiador tomar em consideração o cruzamento de diferentes temporalidades: do acontecimento, da conjuntura e da estrutura. Parece ser potente, para as pesquisas, considerar também o espaço nesse entrecruzamento.

Posto isso, destaco que não penso a História como neutra, como a verdadeira versão do passado, contínua, linear, progressiva, pautada na ideia de sujeitos fundantes e de origens, celebratória dos rumos escolhidos pelo ser humano no tempo, bem como não tenho privilegiado olhares explicativos binários sobre a realidade. Compreendo a história como processo que, em suas multiplicidades, descontinuidades, brechas e atravessamentos constitui os momentos do passado-presente. Penso a História como narrativa, como trama do passado, como fios que se intersectam na construção do passado, permeado por práticas e representações. Considerando desta forma, entretanto, não significa que esteja aludindo que o trabalho do historiador possa desvincular-se do rigor e do cuidado com o tratamento dos documentos:

O meu ofício (de historiador) consiste em fazer perguntas sobre o homem (sobre o homem de hoje), tentar dar-lhes respostas tendo em conta o comportamento de nossa própria sociedade numa etapa anterior de sua duração. Para isso interpreto vestígios. Esses materiais chegam-me já tratados pela erudição e tenho de os afinar ainda mais. Mas quando os manipulo tenho de respeitar algumas regras. (Duby, 1989, p. 161)

Neste texto apresento algumas reflexões que tenho produzido nas práticas de pesquisa em História da Educação construídas, especialmente, a partir do vínculo teórico com autores da Nova História, com ênfase, na História Cultural. Restrinjo a exposição aos documentos escritos para partilhar as dimensões metodológicas que tenho considerado na produção de pesquisas em História da Educação. 


\section{O problema de pesquisa como norteador para a construção do corpus empírico}

A compreensão de que a qualidade da análise e da interpretação histórica depende das problematizações propostas pelo historiador da educação e que as possibilidades narrativas advém da pertinência do corpus empírico, parece ser consenso entre pesquisadores.

Ao eleger um objeto de pesquisa, o historiador da educação faz uma opção que é sua. Essa escolha é tangenciada pelas dimensões objetivas e subjetivas do contexto de vida e das experiências construídas. Mas concordo com Bauman (1998), quando afirma ser importante

saber que nenhuma escolha deixaria o escolhedor livre da responsabilidade pelas suas consequências - e que, assim, ter escolhido, não significa ter determinado a matéria de escolha de uma vez por todas, nem o direito de botar sua consciência para descansar. (p. 249)

Desse modo, estamos imbricados nas escolhas que fazemos e assumi-las parece ser um caminho. Veyne (1998), ao tratar dos problemas que interessam ao historiador, escreveu que "o interesse do historiador dependerá do estado da documentação, de suas preferências pessoais, de uma ideia que veio à mente, do pedido de um editor" (p. 36), ou seja, parece ser fundamental o reconhecimento de que "a história não é senão respostas a nossas indagações, porque não se pode, materialmente, fazer todas as perguntas, descrever todo o porvir" (p. 37). Há marcas da subjetividade. São escolhas, produzidas a partir de questionamentos, marcados pela presença e uso de documentos, ordenados e tecidos pela trama textual produzida pelo historiador. É preciso saber fazer perguntas, questionar e dialogar com os documentos, pois somente com perguntas é que podemos avançar na produção do conhecimento histórico.

As práticas de pesquisa em História de Educação têm sido referenciadas na construção de um corpus empírico. Como sabemos, a noção de documentos, ampliada pela Nova História ${ }^{1}$, possibilita que qualquer indício de uma época possa ser utilizado, para além dos documentos ditos oficiais. Assim, toda e qualquer produção humana pode vir a ser utilizada nas investigações:

A história faz-se com documentos escritos, sem dúvida. Quando eles existem. Mas ela pode fazer-se, ela deve fazer-se sem documentos escritos, se não os houver. Com tudo o que o engenho do historiador pode permitir-lhe utilizar para fabricar o seu mel, à falta das flores habituais. Portanto, com palavras. Com signos. Com paisagens e telhas. Com formas de cultivo e ervas daninhas. Com eclipses da lua e cangas de bois. Com exames de pedras por geólogos e análises de espadas de metal por químicos. Numa palavra, com tudo aquilo que, pertencendo ao homem, serve o homem, exprime o homem, significa a presença, a atividade, os gostos e as maneiras de ser do homem [e mulher!]. (Febvre, 1989, p. 249)

A já conhecida ampliação da noção de documento produziu necessidades novas e alterou práticas de pesquisa, ressignificando e produzindo novas matizes historiográficas. Esse processo foi especial na historiografia da educação, pois, conforme Galvão, "a

\footnotetext{
1 Destaco alguns autores que me auxiliam a pensar na ampliação das fontes documentais em História: Certeau (2002), Le Goff (1996, 1998), Burke (1992), Veyne (1998) E Chartier (1990, 2002, 2004, 2009). 
ampliação do campo documental na educação pode revelar aspectos fundamentais do processo educacional do passado, contribuindo na tarefa de captar, em outros níveis, a diversidade social" (1996, p. 102), ou seja, a partir desta constatação foi possível pensar numa diversidade de possibilidades ${ }^{2}$ para os estudos históricos em educação:

A história da educação se pergunta perplexa pelo cotidiano escolar de outrora. Tal como outros historiadores que instauraram a outra história ou a história vinda de baixo ou ainda a história de gente comum, trata-se de compreender a história da educação a partir de dentro, como é que se fazia a educação, como eram os comportamentos, de que maneira eram compostas as suas atividades de maneira a atingir seus objetivos, etc, etc. Esse como é certamente a carne e o sangue dos por quês. (Lopes, 1992, p. 111)

No entanto, não bastaria diversificar a base documental, variar as fontes de estudo, se a forma de tratá-las não as considerasse de forma diferenciada, se as questões propostas não estivessem formuladas para tomá-las sempre como produções humanas. Nesse sentido, a importância do entendimento dos documentos ${ }^{3}$, compreendidos como monumentos ${ }^{4}$, acepção que muitos tomam a partir de Le Goff (1996), que por sua vez recorreu a Foucault.

Foucault $(2004,2005)$ destacou que, entre os problemas da historiografia, estava o da crítica do documento. Interrogá-los, interrogarmo-nos sobre o que dizem, por que dizem, a quem dizem: "considerá-los não absolutamente como documentos (de uma significação escondida ou de uma regra em construção), mas como monumentos" (Foucault, 2005, p. 95)

Concretamente, o trabalho do historiador não é o de juntar documentos e escrever a partir deles a História. Todos os documentos que nos chegam do passado são plenos de relações, de jogos de sentido e significação, construídos e preservados no tempo para as gerações futuras. Memórias fragmentadas de um tempo que não conseguiremos jamais tomá-lo em sua totalidade. Assim, documentos precisam ser tomados como monumentos para marcar a diferença na atribuição do sentido, no tratamento dispensado a eles: "nenhum documento é inocente. Deve ser analisado. Todo documento é um monumento que deve ser des-estruturado, des-montado" (Le Goff, 1996, p. 110).

Ao pensar no processo metodológico de análise das evidências ou indícios, pela diversidade de documentos que podem ser mobilizados numa pesquisa, é preciso atentar para a clareza, o rigor e para certas precauções. É Le Goff (1996) novamente que lembra:

\footnotetext{
${ }^{2}$ Interessante lembrar a trilogia organizada por LE GOFF, Jacques e NORA, Pierre com os títulos: História: novos problemas; História: novas abordagens e História: novos objetos.

3 Documento, etimologicamente, conforme o dicionário Houaiss, lat. documentum,i 'ensino, lição, aviso, advertência, modelo, exemplo, indício, sinal, indicação, prova, amostra, prova que faz fé, documento', do v.lat. docére 'ensinar' . Dicionário Eletrônico Houaiss da Língua Portuguesa.

${ }^{4}$ Monumento, etimologicamente, conforme o dicionário Houaiss, lat. monuméntum, moniméntum e moliméntum, $i$ 'o que traz à memória, lembrança e penhor de amor, o que faz lembrar um morto, túmulo, estátua'; ver monit-; f.hist. sXIV moymeto, sXIV muimentos, sXV mojmemtos 'sepulcro', sXV moimento 'edifício majestoso'. Dicionário Eletrônico Houaiss da Língua Portuguesa.

${ }^{5}$ Cabe ressaltar que o entendimento de Foucault para documentos enquanto monumentos veio de Georges Canguilhem, como ele próprio registrou neste texto de 1968 (Foucault, 2005, p. 95). 
O documento não é qualquer coisa que fica por conta do passado, é um produto da sociedade que o fabricou segundo as relações de forças que aí detinham o poder. Só a análise do documento enquanto monumento permite à memória coletiva recuperá-lo e ao historiador usá-lo cientificamente, isto é, com pleno conhecimento de causa. (p. 545)

Os documentos tomados como produções humanas, como indícios, como construções instituidoras de sentidos e significados humanos precisam ser montados e desmontados e nesse processo emergem categorias de análise e delas subcategorias. Paul Veyne afirma que a história é conhecimento por meio de documentos, que tomados pelo historiador são lidos, indícios recorrentes são organizados, selecionados, narrados: "a história seleciona, simplifica, organiza, faz com que um século caiba numa página" (Veyne, 1998, p. 18).

Desse modo, são os questionamentos do pesquisador e, portanto, toda a carga subjetiva, traços da história de vida pessoal de quem pesquisou que marcam presença na interpretação dos documentos ${ }^{6}$. Como afirmou Le Febvre (1989), questionamos o passado com os olhos do presente. ${ }^{7}$ As indagações, as inquietudes, a problemática da pesquisa que na constante comparação de documentos oferece a possibilidade de narrar o passado:

Tudo o que foi, um dia contado de uma forma, pode vir a ser contado de outra. Tudo o que hoje acontecerá terá no futuro, várias versões narrativas. [...] reescrita da História, pois a cada geração se revisam interpretações. [...] a História trabalha com a mudança no tempo, e pensar que isso não se dê no plano da escrita sobre o passado implicaria negar pressupostos. (Pesavento, 2003, p. 16)

Portanto, ao referir-me sobre questões metodológicas, considero tratar de um como, de uma estratégia de abordagem, de um saber-fazer possível entre tantos. Formulada a pergunta, que construiu o tema como objeto a partir de um referencial teórico, como trabalhar os indícios ou traços que chegaram desde o passado?

$\mathrm{Na}$ análise documental, considero a importância das recorrências de evidências ou indícios que emergem a partir das questões de pesquisa. Não basta ter documentos. É preciso articular os indícios que se apresentavam com os questionamentos, construindo uma narrativa histórica plausível, possível, verossímil (Pesavento, 2003).

Idas e vindas aos arquivos, acesso a acervos pessoais e públicos, volume de documentos disponíveis cria a necessidade de sistematização, de categorização por temas, considerando-se o contexto e o objeto pesquisado. Para isso, cada investigador lança mão de seus modos de fazer, desde a utilização de cores, o uso de softwares, os

\footnotetext{
${ }^{6}$ Entendo que "a verdade é sempre e já, interpretação. E interpretar [...] simplesmente como criar, inventar, fabricar. A interpretação é uma atividade produtiva. A interpretação é uma invenção. Quem interpreta não descobre a 'verdade'; quem interpreta a produz. Não se trata de uma atividade hermenêutica - descobrir um significado oculto, preexistente; mas de uma atividade poética - criar um significado novo, inédito. Interpretar: violentar, ajustar, abreviar, omitir, preencher, imaginar, falsear. As diferentes interpretações são resultado de diferentes pontos de vista, de diferentes posições, de diferentes perspectivas [...]. Não existe nenhum ponto único, nenhuma perspectiva global e integradora. Só existem perspectivas múltiplas, divergentes, refratárias à totalização e à integração" (Silva, 2002, p. 39).

${ }^{7}$ Febvre (1989), em diversas passagens, afirma que a pesquisa histórica parte de problematizações do presente: "A história, resposta a perguntas que o homem de hoje necessariamente se põe. [...] Organizar o passado em função do presente é aquilo a que poderíamos chamar a função social da história" (p. 49 e 258).
} 
quadros-síntese, dentre outros procedimentos que viabilizam a organização das categorias de análise. Construído o corpus documental, será preciso atentar para as diferentes linguagens mobilizadas pelo documento e as especificidades exigidas para a leitura de cada uma delas ${ }^{8}$.

$\mathrm{Na}$ contemporaneidade o armazenamento de grandes volumes de informação - no caso de documentos históricos digitais e de acervos arquivísticos inteiros em formatos disponibilizados na web - tem facilitado os acessos, usos e cruzamentos de informações. Mas não podemos nos iludir: em certos objetos de pesquisa ou momentos da pesquisa, a ida ao arquivo e o contato com a documentação continuam sendo fundamentais ${ }^{9}$.

\section{A análise documental e a escrita da história da educação}

$\mathrm{Na}$ análise do corpus construído o pesquisador cria formas mais adequadas para o seu objeto e problema de pesquisa, de percepção de recorrências, regularidades e irregularidades. Mas não há um modo único de fazê-lo. Para Chartier (1990) "o modo como em diferentes lugares e momentos uma determinada realidade social é construída, pensada, dada a ler. [...] supõe vários caminhos" (p. 17).

A leitura, como ensina Chartier (1991), no caso dos documentos, "não é somente uma operação abstrata de intelecção: é por em jogo o corpo, é inscrição num espaço, relação consigo ou com o outro. [...] redescobrir os gestos esquecidos, os hábitos desaparecidos" (p. 181). Ao realizar a análise documental, acredito que é fundamental tomar tais elementos como norteadores.

O documento não é uma produção natural ${ }^{10}$, sua preservação e manutenção no tempo, também não. Na análise documental considero relevante perguntarmo-nos: Qual o contexto social, cultural, econômico e político em que esse documento foi produzido? Quem o escreveu? De que lugar social? Para quem escreveu? Quem foram os seus interlocutores? Quais opiniões, informações e discursos são colocados? Que indícios discursivos são reforçados?

No atravessamento dos documentos, perceber as recorrências, os indícios como formas de pensar a educação e as múltiplas relações sócio-político-econômicas, que produzem os discursos. Como já dito, importa lembrar que os documentos não podem ser considerados como um conjunto de informações dadas, que falam por $\mathrm{si}^{11}$. Na análise de documentos textuais, tenho tido em conta seis preocupações principais que se relacionam à concepção do documento, pensado como uma prática e uma realização social: 1) as condições de produção do documento; 2) os procedimentos internos; 3) as condições de circulação do documento; 4) a materialidade do documento; 5) a apropriação; 6) a preservação.

\footnotetext{
${ }^{8}$ Não é demais lembrar que a análise de um jornal requer atentar para especificidades diferenciadas daquelas mobilizadas para analisar um livro didático. Assim, pesquisas que reúnem legislação, objetos, fotografias, cartas, relatórios, cadernos e outros tantos documentos que poderiam ser listados, precisam ser contingenciados pelo olhar cuidadoso do pesquisador que os analisa.

${ }^{9}$ Ver mais em Figueiredo (1997), Tavares (2012) e Samara, Tupy (2007).

10 Uso a expressão produção natural no sentido de algo que decorre normalmente da ordem das coisas, feito de maneira espontânea.

11 "As fontes ou documentos não são um espelho fiel da realidade, mas são sempre a representação de uma parte ou momento particulares do objeto em questão. Uma fonte representa muitas vezes um testemunho, a fala de um agente, de um sujeito histórico; devem ser sempre analisadas como tal" (Borges, 1994, p. 61).
} 
No que concerne às condições de produção ${ }^{12}$ do documento, penso que seja necessário considerar quem exerce a função autor do escrito: se um indivíduo ou corpo editorial para periódicos, ou signatários para manifestos, abaixo-assinados, solicitações, ou órgãos públicos para publicações oficiais, ou editoras em caso de publicação. Também é importante perguntar-se para quem se destina o documento: destinatários ou leitores hipotéticos ou efetivos. Qual o contexto social, político e cultural de sua produção? Quais as relações de poder imbricadas? Negociações? Consensos? Conflitos? Percebo disputas e tensões sociais? Pensar nos procedimentos de exclusão - interdição e vontade de verdade.

Quanto ao segundo item, os procedimentos internos, tenho tentado perceber: o que está escrito: ideias principais e secundárias, e o como está escrito: quais os procedimentos e gênero da escrita, quais os encadeamentos discursivos produzidos.

O terceiro item, referindo as condições de circulação do documento, atento para o lugar em que foi localizado: se em arquivo, biblioteca, acervo pessoal. Pergunto-me sobre informações referentes à distribuição, publicação, se pode ou foi encontrado em outros lugares, se há dificuldades ou facilidades de acesso. Também as características da circulação, ampla ou restrita, remissão do texto em outros documentos, se for o caso.

No quarto item, atentando para a materialidade do documento, convém analisar o tipo, as dimensões, o peso e as condições de funcionamento do suporte em que o documento se apresenta. Qual o material utilizado? Quais as dimensões? Que ênfases percebo? O que diz ou deixa de dizer e é possível perceber?

Para pensar a dimensão de apropriação ${ }^{13}$, considero relevante observar se há marcas inscritas no texto que demostrem usos ou leitura. Há citação do texto em outros documentos? Por exemplo, recortes e ênfases ou escolhas e exclusões? Que possibilidades, ao analisar o documento, tenho para perceber os usos que dele foram feitos?

O sexto item, preservação, considera a localização do documento: em que local estava guardado? Por quem foi preservado? Por que motivos? Qual a posição e condição na organização do acervo? Ou seja, pensar nas razões e condições de sua preservação na relação entre guarda e descarte, na construção da memória ${ }^{14}$, na relação entre o que se quer lembrar e esquecer.

Considerar séries documentais para além de unidades isoladas, promovendo cruzamentos e contraposições entre elas a fim de produzir a compreensão dos sentidos. Diferentes documentos - textuais, orais ou iconográficos - podem ser relacionados para enriquecer a interpretação. Não há dúvida que, na análise documental, o diálogo com

${ }^{12}$ Revel (2009) considera que "o que é dito, pensado, escrito e recebido no seio de uma dada sociedade, mas uma série de contextos que devem permitir especificar não somente os usos que são feitos das palavras e conceitos, mas também as "intenções" que foram as dos autores em situações históricas particulares e que é importante reconstituir" (Revel, 2009, p. 134).

${ }^{13}$ Não é demais lembrar, com Chartier (2004) que as práticas são criadoras de usos e de representações que não podem ser reduzidas às intenções dos produtores de discursos, normas, textos... Há um espaço criativo dos usos, como também considera Certeau (1994).

${ }^{14}$ Podemos nos questionar porque alguns cadernos são preservados e outros descartados, alguns livros mantidos e outros não. Enfim, o que explica a preservação ou o descarte documental. Como ponderou Chartier "para dominar sua inquietação, elas fixaram, por meio da escrita, os traços do passado, a lembrança dos mortos ou a glória dos vivos e todos os textos que não deveriam desaparecer. [...] a escrita teve por missão conjurar contra a fatalidade da perda. [...] Embora temido, o apagamento era necessário, assim como o esquecimento também o é para a memória" (Chartier, 2007, p. 9). 
referências especializadas também é importante para a construção da análise. Para isso, a importância da realização de estados da arte sobre o objeto de estudo. Idas e vindas dos arquivos e acervos, relações com a fundamentação teórica e um cuidado sensível em entrecruzar teoria, empiria, bibliografia e autoria. Atentar para o fascínio que muitos têm pelos arquivos, o que resulta em descrições exaustivas das fontes sem um olhar analítico. Ressalto, ainda, a importância de ser cuidadoso com as referências de localização do documento para que, se necessário, se possa retornar ao arquivo.

Temos então, a tessitura da escrita. O historiador constrói um discurso, uma narrativa que vai sendo entrecortada por notas e citações. Dialogando com outros autores, mas especialmente com documentos de época, o texto produzido é apropriação da palavra do outro, à sua maneira, para dar sentido ao seu próprio texto. Como afirma Prost (2008, p. 241), "trata-se de uma palavra recortada, desmembrada, desconstruída e reconstruída pelo historiador que volta a utilizá-la no lugar de sua escolha em função das necessidades do seu tema". Mas vai além. A citação, seja documental ou bibliográfica, confere sentido e legitimidade à narração do próprio historiador. Certeau (2002) já dizia que a citação produzia um efeito de verdade e ao mesmo tempo, de realidade. Mas é o historiador que recorta, que produz, constrói e reconstrói as citações. Veyne (1998), de modo semelhante, aponta que, na operação de escrita do texto histórico, "o historiador pode dedicar dez páginas a um só dia e comprimir dez anos em duas linhas" (p. 27). Há lacunas nas narrativas que produzimos, assim como no conjunto de documentos que constituem o corpus empírico de nossas pesquisas. Assim, "um acontecimento só é conhecido mediante indícios e que qualquer fato da vida de todos os dias é indício de algum evento" (Veyne, 1998, p. 32).

É Prost (2008) que fundamenta o pensar da produção textual advinda do trabalho do historiador. Para ele,

o texto do historiador é da ordem do conhecimento: trata-se de um saber que se desdobra e se expõe. Ele procura a razão do que se passou: dá explicações e apresenta argumentos. Recorre a conceitos, cujo processo de elaboração não é homogêneo, de qualquer modo, serve-se de noções. Trata-se de um texto relativamente abstrato. (p. 244)

$\mathrm{Na}$ escrita análises são realizadas, construindo-se distinções e aproximações, verificando mudanças, permanências e considerando o individual e o coletivo, o singular e o plural, porque a História "se faz refletindo e, escrevê-la, é uma atividade intelectual" (Prost, 2008, p. 244). Mas essa escrita narrativa, de que se serve o historiador na elaboração de seu texto, não se afasta totalmente da imaginação. Há diversos momentos em que, na tessitura textual, o historiador recorre à ela, assim como produz efeitos de sentido que fazem o leitor recorrer à sua própria imaginação.

Parece importante, no exercício da escrita, atentar ainda para outra advertência necessária: expressarmos o passado com as palavras do presente. Mas como traduzir o que passou, presentificando-o em nossa escrita? É possível? Lembro do exemplo da profissão de jornaleiro: forma como eram registrados os profissionais que trabalhavam por jornada e o entendimento que pode causar para um leitor se relacionar com os dias atuais, no sentido mais corriqueiro, como aquele que entrega jornais. 
Ginzburg (2007) postula que o fio do relato nos ajuda a orientarmo-nos no labirinto da realidade com os rastros. Os documentos abrem leques amplos de possibilidades narrativas. Defende, ainda, que a narração histórica se serve de elementos construtivos que são os mesmos das narrativas ficcionais, mas difere delas por pleitear a produção de representações da realidade. Isso significa compreender que os documentos incluem, para além das intenções de quem o produziu, elementos incontrolados. Observe-se o caso de algumas fotografias que, apesar de não serem o foco dessa análise, ilustram bem o caso apontado por Ginzburg de vozes incontroladas dos documentos. Em minhas pesquisas, a predominância dos documentos fotográficos encontrados revelam momentos que correspondiam aos exames finais. Celebrados e ritualizados, tinham no momento do registro fotográfico, a preparação usual que era esperada para momento tão importante.

Figura 1

Professora Núncia Bascú e seus alunos da capela Santa Lúcia, Nona Légua, Caxias do Sul, década de 1920. Ao fundo, a capela Santa Lúcia.

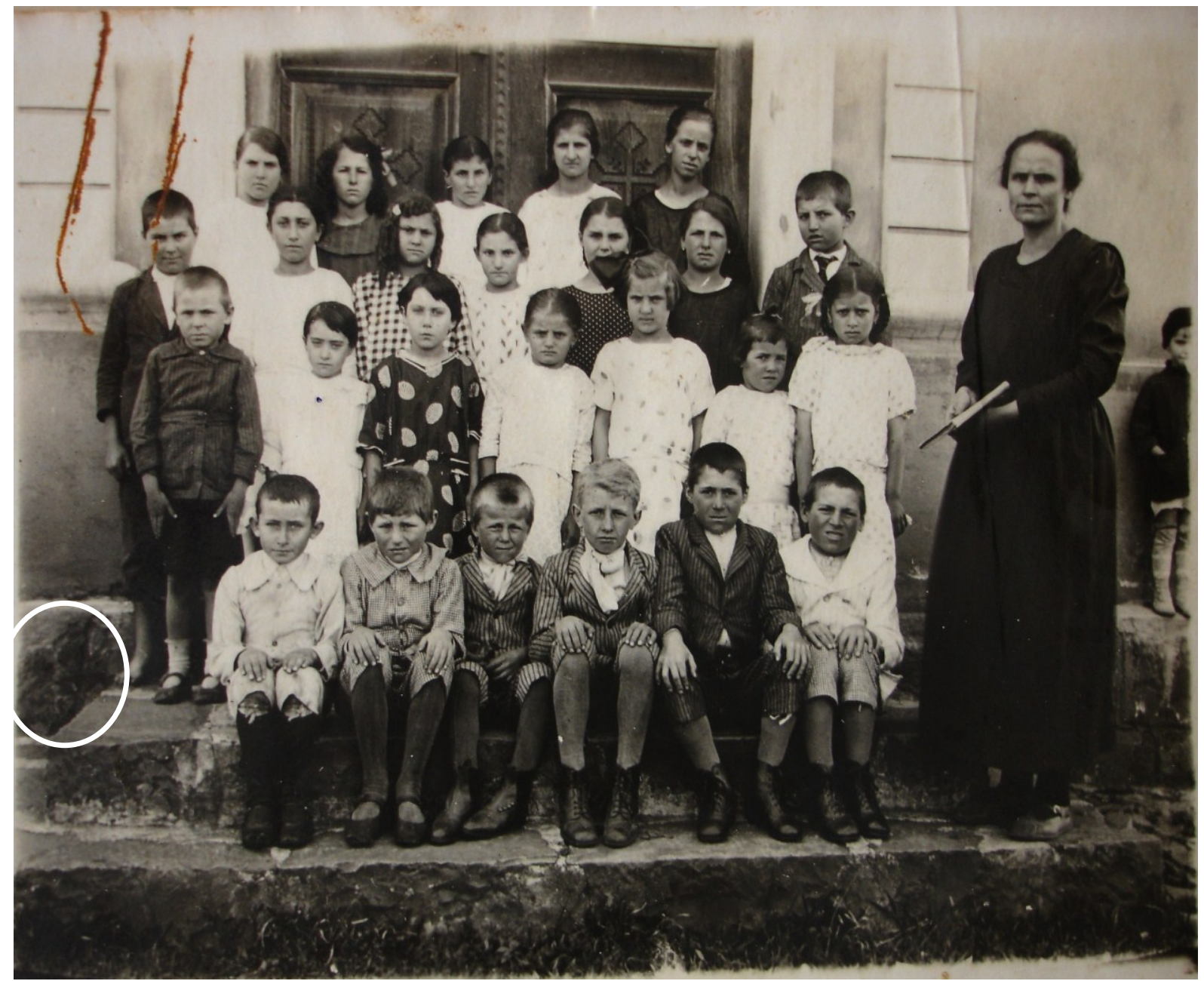

Fonte: A0416, doação de Suely Bascú, Arquivo Histórico Municipal João Spadari Adami.

Não é novidade que a maioria dos alunos seguiam para as escolas da região colonial italiana do Rio Grande do Sul de pés descalços e que, ao se aproximarem da escola, ou já nela, é que calçavam chinelos de couro ou madeira, ou ainda algum sapato, em geral muito maior do que o pé do dono. Mas pés descalços em momentos festivos e 
numa fotografia não ficavam bem. Especialmente se estivessem pouco asseados. Melhor escondê-los, encobri-los. Mas a imagem, por vezes, foge da intencionalidade e o não desejado fica registrado. O historiador precisa atentar para as minúcias, para os detalhes. Novamente, é Ginzburg (2002) que alerta:

As fontes não são nem janelas escancaradas, como acreditam os positivistas, nem muros que obstruem a visão, como pensam os cépticos: no máximo poderíamos compará-las a espelhos deformantes. A análise da distorção específica de qualquer fonte implica já um elemento construtivo. (p. 44)

Outro exemplo de documento fotográfico que evidencia a mesma estratégia de dispor, ao fundo da imagem, aquele que estava descalço, está na figura 2.

Figura 2

Alunos e professor de escola isolada municipal de Garibaldi/RS, década de 1940.

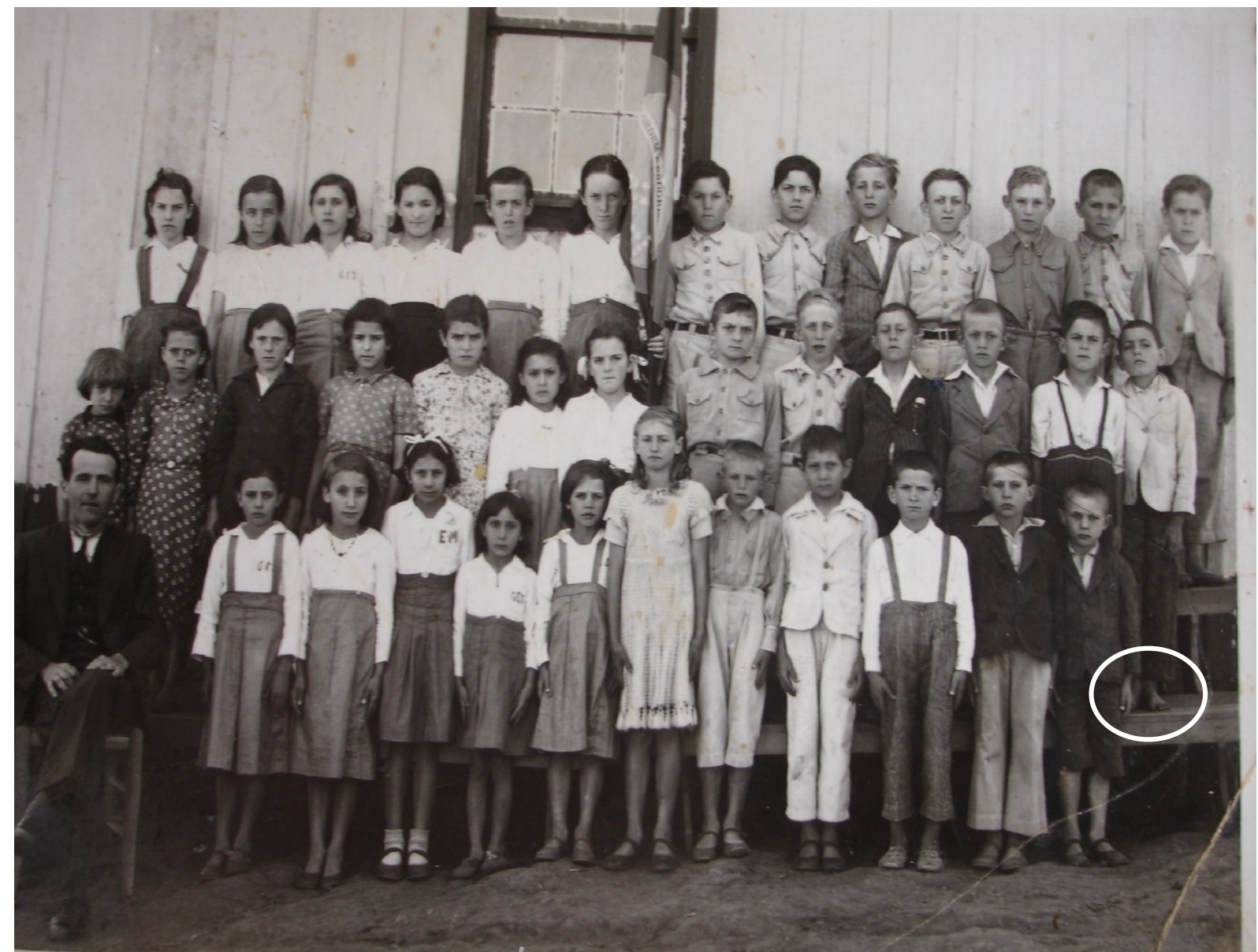

Fonte: acervo fotográfico do Arquivo Histórico Municipal de Garibaldi.

Observe-se em outra fotografia, dos alunos do Colégio Santo Antônio, escola confessional mantida pelos irmãos Maristas e muito reconhecida pela qualidade educacional no município de Garibaldi. Provavelmente a ordem era que todos os alunos cruzassem os braços para o registro fotográfico. A estratégia, para lembrar Certeau 
(1994), era que assumissem a postura de seriedade e ordem esperada, já que eram alunos de um colégio renomado. Mas as táticas subvertem e os usos produzem outras possibilidades, abrem chaves de leitura do documento que em nossa operação de pesquisa precisamos atentar.

Figura 3

Alunos do Colégio Santo Antônio de Garibaldi/RS, s/d.

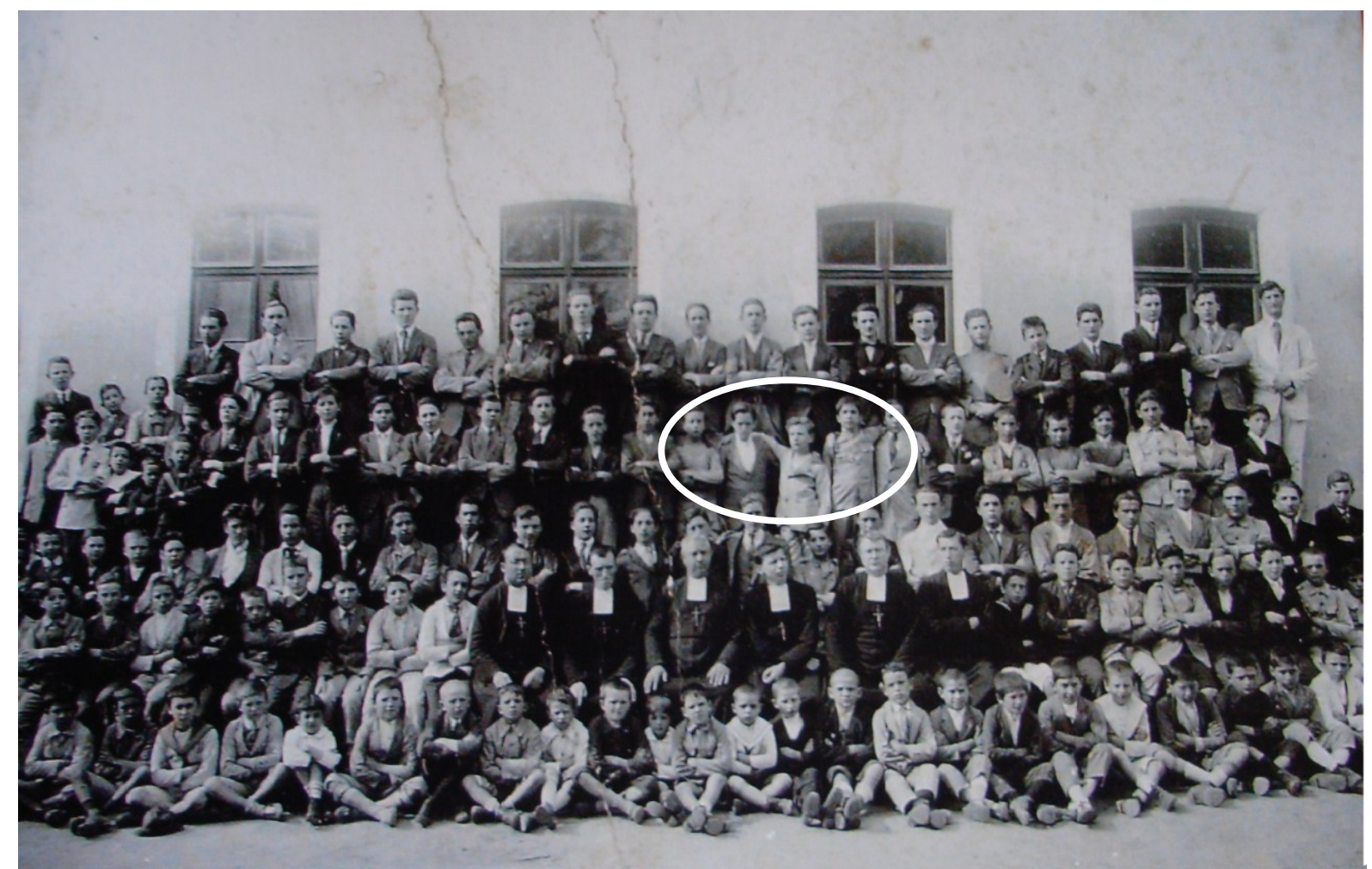

Fonte: acervo fotográfico do Arquivo Histórico Municipal de Garibaldi.

Outro exemplo identificado nas pesquisas que tenho realizado é o de um relatório sobre o movimento de exercício e frequência da aula mista. Relatando sobre sua prática pedagógica, a professora responsável pela aula mista de Caxias escrevia que frequentavam a aula meninos e meninas, alguns ainda analfabetos, tendo eliminado alguns, pois eram "todos mais ou menos inteligentes, de boa índole, muito assíduos na aula, mas pouco aplicados" (Relatório do exercício, 1897) e filhos, em sua maioria, de estrangeiros. Acreditava que

a palavra e os castigos morais não são suficientes para os alunos de educação pouco esmerada, e que infelizmente formam a grande maioria na escola primária. Também não possuímos meios de emulação que provoquem nas crianças desejos de aplicação, para o que lembro dos prêmios que deem direito a livros e outros objetos concernentes a literatura. (Relatório do exercício, 1897).

A professora sugeria, portanto, que a disciplina pudesse ser buscada pelo oferecimento de premiações, o que aparece, com frequência, em atas de exames finais em anos posteriores. Comentando sobre o método pedagógico, explicava que empregava o método misto. A descrição é ilustrativa para se pensar o fazer pedagógico. Indica que 
os alunos mais adiantados, $1^{a}$ seção, eram responsáveis pelas turmas da $2^{a}$ seção. Utilizavam-se da intuição e, ao mesmo tempo, da memorização, na medida em que as lições eram tomadas individualmente pela professora. O método misto era a metodologia usada, como apregoava a pedagogia moderna. É preciso mencionar que o relatório fora elaborado para enviá-lo ao inspetor escolar. Que relações de poder permeiam esta produção discursiva sobre a própria prática pedagógica?

Na maioria das escolas prevalecia o ensino pautado na repetição, na memorização e os castigos ultrapassavam palavras, eram físicos. O silêncio, a obediência, a ordem, a aplicação nos estudos foram padrões de conduta escolar esperados, desejados e cobrados. A socialização escolar das crianças foi pensada e praticada tendo por base o controle dos corpos, dos conhecimentos e da moral. As regras de civilidade foram impressas nos livros, mas buscou-se difundi-las também no cotidiano das salas de aula. No espaço da sala de aula, encontro de culturas e de línguas, da professora que se comunicava em português com crianças que falavam diversos dialetos, dependendo da região de origem das famílias, o processo educativo pode ter sido diverso daquele apontado no relatório da professora. Mas há outra questão: a descrição utilizada pela professora é muito próxima ao que se encontra no Compêndio de pedagogia do professor Pontes, localizado em arquivo pessoal de docente que viveu na região colonial italiana do Rio Grande do Sul.

\section{Quadro 1}

Comparativo entre o relatório de exercício de 1897 e o Compêndio de pedagogia de 1873.

\begin{tabular}{|c|c|}
\hline Relatório de exercício - 1897 & \\
\hline 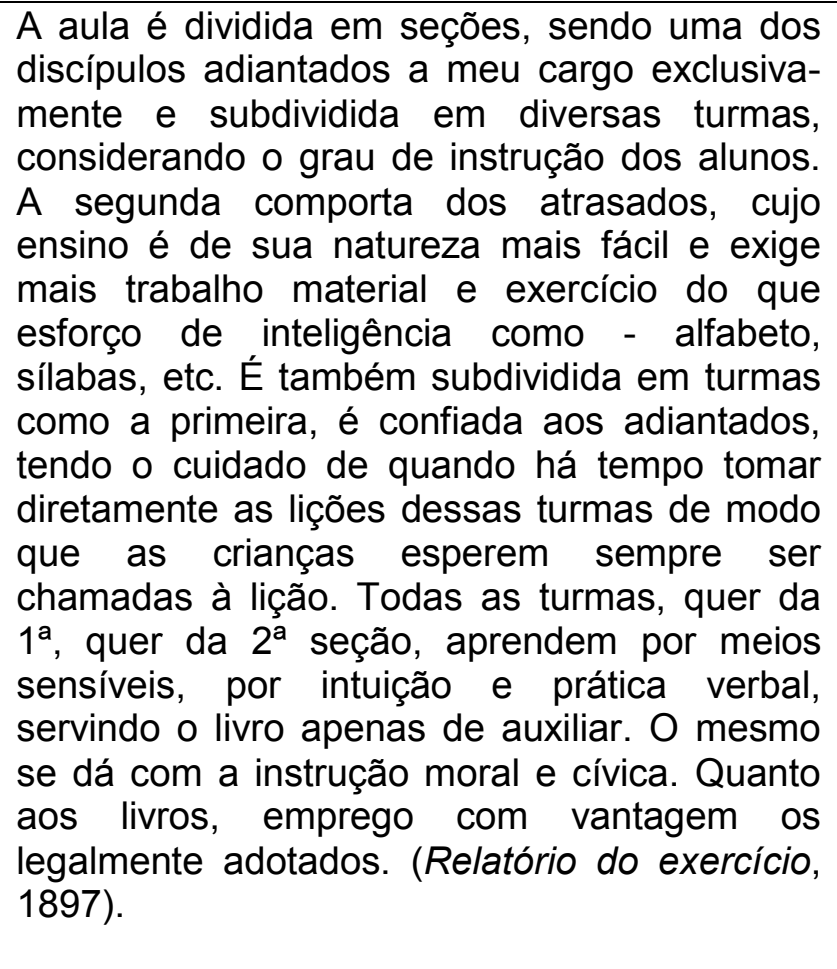 & 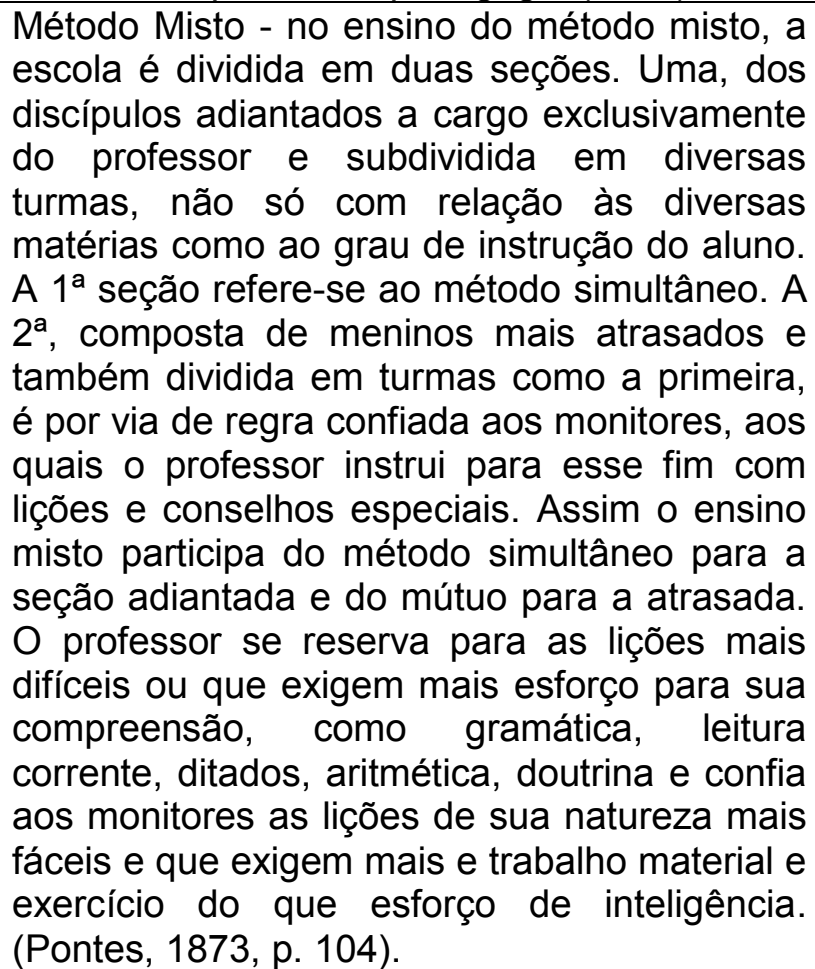 \\
\hline
\end{tabular}


Em minhas práticas de pesquisa tenho aprendido que nem sempre conseguimos responder, com os documentos que nos foram possíveis localizar, todos os questionamentos que temos. Mas para um historiador da educação são as questões que nos movem e que direcionam nosso olhar para perscrutar indícios, rastros, sinais, mesmo quando não conseguimos elaborar respostas. Foi Ginzburg (2007) que me faz pensar em outra precaução metodológica: "zonas opacas são alguns dos rastros que um texto (qualquer texto) deixa atrás de si" (p. 12). Há lacunas, há zonas opacas nos conjuntos documentais que analisamos. Enxergá-los, reconhecendo-os é necessário para que a narrativa histórica que produzimos contingencie a complexidade do passado, as suas descontinuidades.

Na operação historiográfica, Veyne (1998) reconhece a importância de contar como as coisas se passaram, porém o "historiador só tem acesso direto a uma porção ínfima desse concreto, a que the chega pelos documentos de que pode dispor; para todo resto ele precisa tapar os buracos" (p. 118), ou seja, no confronto, na interligação entre os indícios operamos com a síntese histórica que nada mais é do que um processo de preenchimento, por que sempre há lacunas nos documentos, o que inclui tapar buracos como refere Veyne (1998) ou, talvez, ao menos mencionar e enxergar sua existência. Reconhecendo a necessidade de inferências por parte do historiador, responsável pelas conexões, afirma ainda que "a experiência histórica é, pois, composta de tudo que um historiador pode aprender aqui e ali em sua vida, em suas leituras e em sua convivência com outrem" (Veyne, 1998, p. 126). Seria a erudição, mencionada também por Pesavento (2003). A análise documental é tanto mais rica, quanto maior for o repertório do investigador. Boutier e Julia (1998) conferem relevância à lógica da acumulação, relacionando com os procedimentos do métier do historiador:

Acumulação de instrumentos de trabalho e de dados (repertórios de arquivos e de fontes, bibliografias gerais ou especializadas, dicionários, edições de textos, bancos de dados...), acumulação de trabalhos... Mas não está aí o essencial: a qualidade da produção histórica depende do questionário elaborado pelo historiador; a validade das respostas obtidas remete, além dos procedimentos empregados, à pertinência da documentação mobilizada em relação às questões propostas. (Boutier; Julia, 1998, p. 38)

Boutier e Julia (1998) apontam para alguns elementos a considerar na realização das pesquisas históricas para que elas ganhem em qualidade. No conjunto de reflexões apresentadas nessas páginas partilhei algumas das alternativas e também pressupostos que tenho considerado.

\section{Considerações finais}

O trabalho do historiador da educação, que se debruça a investigar objetos com recorte regional, precisa dar conta de um conjunto de procedimentos metodológicos para os quais, ao longo desse texto, tentei apontar, especialmente no que se refere à análise de documentos escritos.

Para finalizar, partilho um trecho escrito por Bauman (2001), em que ele estabelece uma correlação entre o poeta e a sua condição de sociólogo: 
O que a história faz corriqueiramente é um desafio, uma tarefa e uma missão para o poeta. Para elevar-se a essa missão, o poeta deve recusar servir verdades conhecidas de antemão e bem usadas, verdades já óbvias por que trazidas à superfície e aí deixadas a flutuar. [...] essas verdades não são as coisas ocultas que o poeta é chamado a desvelar; são antes partes da muralha que é missão do poeta destruir. Os porta-vozes do óbvio, do auto-evidente e daquilo em que todos acreditamos são falsos poetas. (Bauman, 2001, p. 231)

No meu caso, o questionamento toca de forma diferenciada. O que tem a ver o poeta e o historiador da educação e os próprios pesquisadores em educação? Como os poetas, precisamos questionar as verdades dadas, naturalizadas nos discursos. Eis o desafio: desconstruir, desnaturalizar, virar pelo avesso. As investigações precisam considerar estes desafios, bem como ter o rigor necessário para a construção de uma versão interpretativa plausível, possível, com certezas provisórias e que estabeleçam relações de verossimilhança. Parece ser uma boa postura metodológica aquela em que o

trabalho consiste em criar ausentes, em fazer, de signos dispersos na superfície de uma atualidade, vestígios de realidades "históricas" ausentes porque outras. [...] Esta é a história. Um jogo da vida e da morte prossegue no calmo desdobramento de um relato, ressurgência e denegação da origem, desvelamento de um passado morto e resultado de uma prática presente. (Certeau, 2002, p. 57)

Nesse jogo de vida-morte, de passado-presente, de documentos-monumentos, não podemos esquecer que as narrativas históricas da educação, derivadas das pesquisas que produzimos, são resultado de trabalho com questões de pesquisa possíveis no tempo em que vivemos e que, para respondê-las, construímos um corpus empírico de indícios, rastros, sinais que são ordenados, montados, questionados na análise, na interrelação e contextualização que procedemos para escrever. Escrever um possível sobre o passado educacional.

\section{Referências}

ALBUQUERQUE JÚNIOR, Durval Muniz de. A invenção do nordeste e outras artes. São Paulo: Cortez, 2011.

BAUMAN, Zygmunt. O mal-estar da pós-modernidade. Rio de Janeiro: Jorge Zahar, 1998. BAUMAN, Zygmunt. Modernidade líquida. Rio de Janeiro: Jorge Zahar, 2001.

BORGES, Vavy Pacheco. O que é história. São Paulo: Brasiliense, 1994.

BOUTIER, Jean; JULIA, Dominique. Introdução - Em que pensam os historiadores? In: BOUTIER, Jean; JULIA, Dominique (orgs.). Passados recompostos: campos e canteiros da história. Rio de Janeiro: UFRJ/FGV, 1998, p. 21-61.

BRAUDEL, Fernand. Reflexões sobre a história. São Paulo: Martins Fontes, 2002.

BURKE, Peter. Escrita da história: novas perspectivas. São Paulo: Unesp, 1992.

CERTEAU, Michel de. A escrita da história. Rio de Janeiro: Forense Universitária, 2002.

CERTEAU, Michel de. A invenção do cotidiano 1: artes do fazer. Petrópolis: Vozes, 1994. 
CHARTIER, Roger. À beira da falésia: a história entre certezas e inquietude. Porto Alegre: Ufrgs, 2002.

CHARTIER, Roger. A história cultural: entre práticas e representações. Rio de Janeiro: Bertrand, 1990.

CHARTIER, Roger. A história ou a leitura do tempo. Belo Horizonte: Autêntica, 2009.

CHARTIER, Roger. Inscrever e apagar: cultura escrita e literatura. São Paulo: Unesp, 2007.

CHARTIER, Roger. Leituras e leitores na França do antigo regime. São Paulo: Unesp, 2004.

CHARTIER, Roger. O mundo como representação. Estudos Avançados, v. 5, n. 11, 1991, p. 173-191.

DUBY, Georges. Diálogos sobre a nova história. Lisboa: Dom Quixote, 1989.

FEBVRE, Lucien. Combates pela história. Lisboa: Presença, 1989.

FIGUEIREDO, Luciano R. História e informática: o uso do computador. In: CARDOSO, Ciro F; VAINFAS, Ronaldo (orgs.). Domínios da história: ensaios de teoria e metodologia. Rio de Janeiro: Campus, 1997, p. 419-439.

FOUCAULT, Michel. A arqueologia do saber. Rio de Janeiro: Forense Universitária, 2004.

FOUCAULT, Michel. Sobre a arqueologia das ciências: resposta ao círculo da epistemologia. In: MOTTA, Manoel Barros da (org.). Arqueologia das ciências e história dos sistemas de pensamento. Rio de Janeiro: Forense Universitária, 2005, p. 82-118.

GALVÃO, Ana Maria de Oliveira. Problematizando fontes em história da educação. In: Revista Educação e Realidade. Porto Alegre, v. 21, n. 2, 1996, p. 99-118.

GINZBURG, Carlo. O fio e os rastros: verdadeiro, falso, fictício. São Paulo: Companhia das Letras, 2007.

GINZBURG, Carlo. Relações de força: história, retórica, prova. São Paulo: Companhia das Letras, 2002.

JENKINS, Keith. A história repensada. São Paulo: Contexto, 2004.

LE GOFF, Jacques; NORA, Pierre. História: novas abordagens. Rio de Janeiro: Francisco Alves, 1976.

LE GOFF, Jacques; NORA, Pierre. História: novos objetos. Rio de Janeiro: Francisco Alves 1976.

LE GOFF, Jacques; NORA, Pierre. História: novos problemas. Rio de Janeiro: Francisco Alves, 1976.

LE GOFF, Jacques. História e memória. Campinas: Unicamp, 1996.

LE GOFF, Jacques; CHARTIER, Roger; REVEL, Jacques. A história nova. São Paulo: Martins Fontes, 1998.

LOPES, Eliane Marta T.. Fontes documentais e categorias de análise para uma história da educação da mulher. In: Teoria e Educação. Porto Alegre, n. 6, 1992, p. 105-114.

PESAVENTO, Sandra Jatahy. História e história cultural. Belo Horizonte: Autêntica, 2003.

PONTES, Antonio Marciano da Silva. Compêndio de pedagogia (para uso dos alunos da Escola Normal do Rio de Janeiro). Rio de Janeiro: Tipografia da Reforma, 1873.

PROST, Antoine. Doze lições sobre a história. Belo Horizonte: Autêntica, 2008. 
RELATÓRIO DO EXERCíCIO e movimento da aula mista da vila de Caxias apresentado pela professora ao Cidadão Inspetor da $3^{\text {a }}$. Região Escolar em 30/10/1897. Fundo Educação e Cultura - 06.02.01. Arquivo Histórico Municipal João Spadari Adami.

REVEL, Jacques. Proposições: ensaios de história e historiografia. Rio de Janeiro: Uerj, 2009.

SAMARA, Eni de Mesquita; TUPY, Ismênia S. S. T. História, documento e metodologia de pesquisa. Belo Horizonte: Autêntica, 2007.

SILVA, Tomaz Tadeu da. Dr. Nietzsche, curriculista - com uma pequena ajuda do professor Deleuze. In: MOREIRA, Antônio Flávio; MACEDO, Elizabeth Fernandes de. Currículo, práticas pedagógicas e identidades. Porto: Porto, 2002, p. 35-52.

TAVARES, Célia Cristina da Silva. História e Informática. In: CARDOSO, Ciro F; VAINFAS, Ronaldo (orgs.). Novos domínios da história. Rio de Janeiro: Elsevier, 2012, p. 301-317.

VEYNE, Paul. Como se escreve a história e Foucault revoluciona a história. Brasília: UNB, 1998.

TERCIANE ANGELA LUCHESE é professora no Programa de Pós-Graduação em Educação da Universidade de Caxias do Sul.

Endereço: Rua João Luchese, 75 - 95700-000 - Bento Gonçalves - RS - Brasil.

E-mail: taluches@ucs.br.

Recebido em 21 de novembro de 2013.

Aceito em 14 de maio de 2014. 